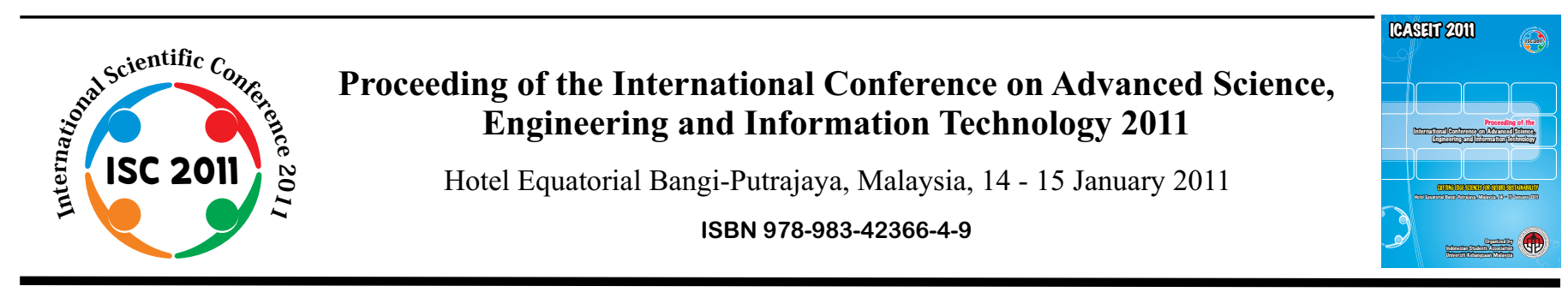

\title{
Predict Incorrect Thinking Process: Negative Numbers Subtraction Operation Second Category
}

\author{
Elango Periasamy ${ }^{1}$ and Halimah Badioze Zaman ${ }^{2}$ \\ Fakulti Teknologi Sains Maklumat, Universiti Kebangsaan Malaysia, Bangi, 43650, Malaysia; \\ ${ }^{2}$ hbzeftsm.ukm.my and ${ }^{1}$ surensutha@yahoo.com
}

\begin{abstract}
This study was divided into two parts. The first part was to identify the incorrect answer produced by the respondent for each item and its frequency. Then, the second part was to predict the ITP with respect to its frequencies that that respondent might have adapted in solving such sentence questions incorrectly. The respondent of this study were five mathematics teachers and 124 students aged 14 years old from Malaysian secondary school. The finding shows types of mistakes made by the students for each type of items tested and the prediction of ITP respectively.
\end{abstract}

Keywords - Negative Numbers, Subtraction, Predict, Teaching and Learning Mathematics

\section{Introduction}

According to [1], the Lower Secondary Examination (PMR) report from the Malaysian examination Board shows that students were unable to master the skills and understanding the abstract concepts that involves negative number operation in fraction, transformation and algebra. Moreover, in the 2002 PMR examination, 47\% showed clear weaknesses in operation involving negative number such as $(-17+14),(-17+22+8),(-17-14)$ and $(-17+30)$ [2]. Such that, a study with 124 students aged 14 year from two secondary schools in Malaysia was carried out by [3] which revealed the existence of difficulties in solving negative numbers subtraction operation involving two integers. This phenomenon is explained by [4] as situations whereby negative numbers extend our number line and greatly simplify our calculations, but sometimes students struggle with the concepts. Nevertheless, according to [5], it is also important for students to determine what things are as well as what they are not, if we are to help them avoid arising at incorrect assumptions, conclusions, thought processes and generalization.

A review of literature shows that teachers were very creative and innovative in teaching the concept of subtraction and addition operation involving negative numbers by integrating various communication tools such as line graph, coloured stones, coloured chips, gain-owe techniques and computer courseware in their effort to help students acquire the knowledge of solving negative numbers subtraction and addition operation. These efforts shows the commitment and creativeness of teachers that should be acknowledged as an ongoing process that are continuously evolving in searching ways and mean to help students acquire knowledge related to subtraction and addition operation in negative numbers. Such that to help students avoid arising at incorrect assumption, conclusions, thought process and generalizations which is also important for them to determine what things are as well as what they are not [5]. Thus, this study was divided into two parts. The first part was to identify the incorrect answer produced by the respondent for each item and its frequency. Then, the second part was to predict the ITP with respect to its frequencies that that respondent might have adapted in solving such sentence questions incorrectly.

\section{Related Works}

According to [6], a central function of the mind is to process the information, sort them in a meaningful way is determined by the rules and principles employed, thus learning is then perceived as appropriating these rules and principles and being able to apply (or process information) according to these rules. In such, the knowledge of how children construct their early knowledge can be effectively gained from observing and interviewing during explicit teacher set tasks, that is if a student compute that $8-5=6$, and from examination of work samples the teacher would immediately conclude that the child was experiencing difficulty with the subtraction process but further observation as the child works through examples: 7-3 = 2; $10-7=3 ; 2-1=4$ the teacher quickly realises the source of the errors that is the child is confusing the digits 2 and 5 [7]. Moreover, a study to refine students' skills of addition and subtraction including negative numbers with a seventh grade student, turned out that errors were due to bug rules 
and the lack of a critical production when executing a purely algebraic solution were identified based on a cognitive task analysis using several possible ways of calculation [8].

Furthermore, findings suggest that adults' representations of operation with negative numbers are not as well established as their representations of operations with positive numbers [9] because in operation involving negative numbers, some students assume many mathematical things to be universally true and because of this they are at times, amazed to realize their assumptions have been false [5]. Such phenomenon was found existed among two secondary school students in Malaysia in solving subtraction operation involving two integers [3]. For example,

some students are not aware that the commutative property for addition operates in sets other than the counting number. A series of questions or problems like $3+{ }^{+} 7=$ and $^{+} 7+{ }^{-} 3=$ could help lead to the appropriate conclusions and can be amplified with problems involving subtraction where commutativity does not generally hold, sometimes that same students assume to be true $\left(-5-{ }^{+} 8=\right.$ and $\left.^{+} 8-5=\right)$.

([5], $P g$ 295)

$\ldots 3+3=6$. Counting it out on your fingers can prove the accuracy of the equation. We can see apples and oranges in clusters of 3 or 6. It is reasonably easy to visualize the concept of addition of positive numbers. But, despite what all our algebra teachers have instructed about negative numbers, when we try to add 3 apples to a pile consisting of a (-3) apples, things do not work out so simply. I get a queasy feeling in my stomach every time I try to work with negative numbers. It makes me quite uneasy to think that my bowl containing 3 apples will be swept off into a vortex and lost forever if I were to add them to a pile containing a minus 3 apples, yet the pile of 3 apples would remain intact if I were to place them into an empty container. The mystery of where the 3 apples would travel absolutely baffles me. And, yet, it would be a rare mathematician who would concede that negative numbers are an illusion. The mathematicians don't care if the rules and concepts they employ are idiotic as long as they can arrive at precise answers time after time. In other words, they know full well that negative numbers are fraudulent, but, since they are useful tools, they are happy to continue with the illusion. To my way of thinking, the smallest number of anything would have to be zero. When there are no apples on the plate, it is empty. It would take a strange metaphysical phenomenon indeed to allow me to place 3 apples on the plate and watch them vanish. Since when did the sceptical people of science allow such portals that consume apples to be considered "normal" behaviour? This is not to say that such portals cannot exist, but it is to say that such portals could not be called upon to operate in a totally predictable manner each and every time someone placed a hyphen before a number converting it from a positive number, or something, into a negative number, or a weird thing that is less than nothing.

([10], $P g$ 3)

Although different strategies were used by various researchers in helping students gain the knowledge of solving negative numbers subtraction operation, nevertheless real objects manipulation for subtraction operation of negative numbers is an illusion. Such that, Stanford claims that students have been given absurd rules to apply to this weird concept, such as a negative number when multiplied by another negative number becomes a positive number which is an unadulterated nonsense [10]. Moreover, to help students avoid arising at incorrect assumptions, conclusions, thought processes and generalization, it is important for students to determine what things are as well as what they are not [5]. In such, the misconception among students need to be addressed such as predicting their ITP which would give a guideline on how to hinder such misunderstanding of negative numbers subtraction operation and an immediate practice of corrective thinking process can be instigated and further difficulties overcome.

\section{Method}

The demographic information of this research was 124 respondents aged 14 years old and among them were 53 boys and 71 girls. The number of respondent achieved a grade A is $26(20.97 \%)$, grade B $58(46.77 \%)$ and grade C $40(32.26 \%)$ for their Primary School Evaluation Examination (UPSR) in mathematics subject. The questionnaires were divided into two sections. The first section consists of demography data to understand the respondent profile. The second section consists of 24 negative number subtraction operation test items and only one correct answer for each item as in Table 1 . Face validity was done with five Mathematics teachers from five schools from a district in Malaysia. Those teachers had an experience of teaching Negative Number topic for at least five years. The questionnaire for this research was created by [3]. A pilot test was carried out [3] with a subject of 35 school students aged 14 years old from a secondary school in Malaysia. The calculation of reliability coefficient using Kuder-Richardson formula is use for dichotomy question with right wrong answer such as the objective questions [11]. The Kuder-Richardson (KR20) reliability estimation value of this instrument is 0.919544 . The reliability is calculated using the KR20 formula [12] with Microsoft Office Excel 2007. According to [12], when the test format has only one correct answer then KR20 is algebraically equivalent to Cronbach alpha. Therefore, in this case the KR20 reliability estimation value of this pilot test is equivalent to Cronbach alpha coefficient.

The 24 items of that research as in Table 1 was rearranged into four categories as follows:

i. First category - Subtraction Operation Involving Two Positive Integers

ii. Second category - Subtraction Operation Involving Negative with Positive Integers 
iii. Third category - Subtraction Operation Involving Negative with Negative Integers

iv. Forth category - Subtraction Operation Involving Positive with Negative Integers

TABLE 1

Negative number subtraction operation test items

\begin{tabular}{cl|c|l}
\hline No & \multicolumn{1}{c|}{ Item } & No & \multicolumn{1}{c}{ Item } \\
\hline 1 & $5-2=$ & 13 & $-8-13=$ \\
\hline 2 & $-5-2=$ & 14 & $8-13=$ \\
\hline 3 & $-5-(-2)=$ & 15 & $-8-(-13)=$ \\
\hline 4 & $5-(-2)=$ & 16 & $8-(-13)=$ \\
\hline 5 & $-2-5=$ & 17 & $16-23=$ \\
\hline 6 & $2-5=$ & 18 & $-16-23=$ \\
\hline 7 & $-2-(-5)=$ & 19 & $-16-(-23)=$ \\
\hline 8 & $2-(-5)=$ & 20 & $16-(-23)=$ \\
\hline 9 & $13-8=$ & 21 & $-23-16=$ \\
\hline 10 & $-13-8=$ & 22 & $23-16=$ \\
\hline 11 & $-13-(-8)=$ & 23 & $-23-(-16)=$ \\
\hline 12 & $13-(-8)=$ & 24 & $23-(-16)=$ \\
\hline
\end{tabular}

In such, each category consist of 6 items with respect to its theme. The focus of this study was limited to the second category to predict about the ITP of subtraction operation involving negative with positive integers $(a-b, a<0, b>0)$ only.

In conjunction, this study was divided into two parts. The first part was to identify the incorrect answer produced by the respondent for each item and its frequency for the second category. Then, the second part was to predict the ITP with respect to its frequencies that that respondent might have adapted in solving such sentence questions incorrectly. In such, all possible ITP that student would have used in order to arrive at those wrong answers need to be derived explicitly by analyzing students prior knowledge and teachers teaching approach for negative numbers subtraction operation that might have responsible for such conflict in adapting the correct thinking or rules in solving subtraction operation. Then, re-confirming with three mathematics teachers.

\section{Findings}

The first part was to identify the incorrect answer produced by the respondent for each item and its frequency. Table 2 shows the result of the first part of this study. The highest incorrect solution was for item $18(63.71 \%)$ whereby 47 , 14 and 18 students gave incorrect solution 39, -7 and 7 respectively, followed by item $13(62.10 \%)$ whereby 23,40 and 14 students gave incorrect solution 5, 21 and -5 respectively, then item 10 and item 21 (60.48\%) whereby 38,32 and 5 students gave incorrect solution $21,-5$ and 5 respectively for item 10 meanwhile 38,32 and 5 students gave incorrect solution $39,-7$ and 7 respectively for item 21 , continued by item $5(53.23 \%)$ then 42,10 and 14 students gave incorrect solution $7,-3$ and 3 respectively and finally item $2(52.42 \%)$ whereby 30 and 35 students gave incorrect solution -3 and 7 respectively.

The second part was to predict the ITP with respect to its frequencies that that respondent might have adapted in solving such sentence questions incorrectly. In such, the finding was further separated into two groups (G1 and G2) to better address and predict its ITP. Furthermore, an example was used to recapture the ITP of respondent and two integers selected randomly for these purpose was 15 and 7.

TABLE 2

Subtraction of negative with positive integer

\begin{tabular}{ccccc}
\hline No & Item & $\begin{array}{c}\text { Incorrect } \\
\text { Solution }\end{array}$ & Frequency & $\begin{array}{c}\text { Total } \\
(\%)\end{array}$ \\
\hline 2 & $-5-2=$ & -3 & 30 & 65 \\
& & 7 & 35 & $(52.42 \%)$ \\
\hline 5 & $-2-5=$ & 7 & 42 & 66 \\
& & -3 & 10 & $(53.23 \%)$ \\
\hline 10 & $-13-8=$ & 21 & 14 & \\
& & -5 & 38 & $(60.48 \%)$ \\
& & 5 & 5 & \\
\hline 13 & $-8-13=$ & 5 & 23 & 77 \\
& & 21 & 40 & $(62.10 \%)$ \\
& & -5 & 14 & \\
\hline 18 & $-16-23=$ & 39 & 47 & 79 \\
& & -7 & 14 & $(63.71 \%)$ \\
& & 7 & 18 & \\
\hline 21 & $-23-16=$ & 39 & 38 & 75 \\
& & -7 & 32 & $(60.48 \%)$ \\
& & 7 & 5 & \\
\hline
\end{tabular}

TABLE 3

Incorrect Thinking Process G1

\begin{tabular}{cll}
\hline ITPG1 & \multicolumn{1}{c}{$\begin{array}{c}\text { Incorrect } \\
\text { Solution }\end{array}$} & \multicolumn{1}{c}{ Predict ITP } \\
\hline & & Move 1: Perform 15-7 which gives \\
1 & $-15-7=8$ & 8.
\end{tabular}

Move 2: Negative sign in front number 15 multiply negative sign in front number 7 which give the sign for final answer, in this case positive. Thus $-15-7=8$ Move 1: Perform $15-7$ which gives

$2-15-7=-8 \quad 8$.

Move 2: Now, number 15 is bigger than number 7 and having negative sign, then conclude that the final answer must follow negative sign, thus, $-15-7=-8$

Move 1: Negative sign in front $3 \quad-15-7=22$ number 15 multiply negative sign in front number 7 which become positive and the sentence question is rewritten as $15+7$.

Move 2: Perform 7+15 which would give 22 , thus $-15-7=22$.

G1 addresses subtraction operation involving magnitude value of first negative integer bigger than magnitude value of second positive integer (ITPG1). Table 3 shows that ITPG1 has three incorrect solution produce from three different thinking process ITPG1-1, ITPG1-2 and ITPG1-3 and the predict ITP column derives the process of it respectively with move 1 and move 2 to further recapture the ITP that might have used by respondent. In such, a similar item in the form of ITPG1 " $-15-7$ =" was used. Whereas, G2 addresses subtraction operation involving magnitude value of first negative integer smaller than magnitude value of second positive integer (ITPG2). Table 4 shows that ITPG2 has three incorrect solution produce 
from three different thinking process ITPG2-1, ITPG2-2 and ITPG2-3 and the predict ITP column derives the process of it respectively with move 1 and move 2 to further recapture the ITP that might have used by respondent. In such, a similar item in the form of ITPG1 “$7-15=$ " was used.

TABLE 4

Incorrect Thinking Process G2

\begin{tabular}{|c|c|c|}
\hline ITPG2 & $\begin{array}{l}\text { Incorrect } \\
\text { Solution }\end{array}$ & Predict ITP \\
\hline 1 & $-7-15=8$ & $\begin{array}{l}\text { Move } 1 \text { : negative sign in front } \\
\text { number } 7 \text { multiply negative sign } \\
\text { in front number } 15 \text { which give the } \\
\text { sign for final answer, in this case } \\
\text { positive. } \\
\text { Move } 2 \text { : Now the question } \\
\text { rewritten as } 7-15 \text { (First Group } \\
\text { type of question) and solves } 15- \\
7 \text { which give } 8 \text {. Thus, }-7-15=8\end{array}$ \\
\hline 2 & $-7-15=-8$ & $\begin{array}{l}\text { Move 1: A negative sign in front } \\
\text { of sentence question, thus the } \\
\text { final answer must follow with } \\
\text { negative sign. } \\
\text { Move } 2 \text { : Then, the question } \\
\text { rewritten as } 7-15 \text { (First Group } \\
\text { type of question) and solved as } 15 \\
-7 \text { which gives } 8 \text {. Now from } \\
\text { Move } 1 \text {, the final answer must } \\
\text { follow with negative sign. Thus, - } \\
7-15=8\end{array}$ \\
\hline 3 & $-7-15=22$ & $\begin{array}{l}\text { Move 1: Negative sign in front } \\
\text { number } 7 \text { multiply negative sign } \\
\text { in front number } 15 \text { which become } \\
\text { positive and the sentence question } \\
\text { is rewritten as } 7+15 \text {. } \\
\text { Move } 2 \text { : Perform } 7+15 \text { which } \\
\text { would give } 22 \text {. Thus, }-7-15=22\end{array}$ \\
\hline
\end{tabular}

\section{Discussion}

Items 2, 10 and 21 are subtraction operation of a negative integer which has an absolute value bigger with a positive integer number which is smaller $(\mathrm{a}-\mathrm{b}=, \mathrm{a}<0, \mathrm{~b}>0,|\mathrm{a}|>\mathrm{b})$. Research finding shows that research respondent using three different thinking process technique which gives wrong answer. Between the three thinking process techniques, the ITPG1-3 technique found to be more dominant followed by the ITPG1-2 technique and then the ITPG1-1 technique.

While, items 5, 13 and 18 are subtraction operation of a negative integer number which has an absolute value smaller with a positive integer number which is bigger $(\mathrm{a}-$ $b=, a<0, b>0,|a|<b)$. Research finding shows that research respondent using three different thinking process technique which gives wrong answer. Research finding shows that research respondent using three different thinking process technique which gives wrong answer. However, the ITPG2-3 technique found to be more dominant followed by the ITPG2-2 technique and then the ITPG2-1 technique. Thus, can be concluded that there are three possibilities of wrong thinking process techniques which given by this research respondent.
The process of predicting ITP was a very tedious and time consuming. The process needed special diagnostic sentence questions which could create conflict in the students' thinking process in solving them and with proper analysis and synthesis when predicting ITP and followed by reconfirming the prediction. Nevertheless, this study was an interesting experience towards exploring the ITP respondents acquired, moreover the findings can be important in helping mathematics educators to be aware of such ITP could exist and proper precaution should be taken into consideration during teaching and learning of negative numbers subtraction operation or remedial works. It is because such misconceptions firstly, interfere with learning when students use them to interpret new experiences and secondly, students are emotionally and intellectually attached to their misconceptions because they have actively constructed them and students give up their misconceptions, which can have such a harmful effect on learning, only with great reluctance [13]. But to teach in a way that avoids creating and misconceptions is not possible and we have to accept that students will make some incorrect generalizations that will remain hidden unless the teacher makes specific efforts to uncover them ([14] in [13])

In such, according to [7], there is no simple one answer to guide specific practice and teachers must provide a wide variety of methods through their diverse repertoire of class room practices in their lesson planning, the topic presented, the instructional experiences and activities incorporated in the learning session and their responses to children's questions. Moreover, [5] suggested that assistance is provided to the discovery process through a carefully developed set of problems that guide the student to appropriate responses. Nevertheless, [6] says that by analysing the way the experts think and by teaching students these expert ways of thinking, cognitivists hope to instruct students in order to emulate expert thinking and develop the students' expertise is a particular domain of knowledge.

\section{Conclusion}

In conjunctions, this study was to identify and predict the ITP of respondents in solving negative numbers subtraction operation involving two integer sentence questions limited to single double digit integers. Even though, all students in a class room are taught equally and simultaneously but the way they perceive and process the knowledge are in their own unique way should be acknowledged with great enthusiasm. In such, the most sadness of this study was that the teachers and students were unaware of the existence of the ITP until a study of this kind was conducted.

\section{Future Works}

The future works relevant to this study is the quest to investigate how a strategy can be created and integrated into the instructional model of visualizing correct thinking process involved in negative numbers subtraction operation with the help of technology. 


\section{ACKNOWLEDGEMENT}

We would like to thank The Malaysian Education Ministry, mathematics teachers, students and all whom have had made direct or indirect contribution, commitment, support and concern for the success of this study are highly appreciated and may God bless all.

\section{REFERENCES}

[1] Lembaga Peperiksaan Malaysia. 1993. Laporan Prestasi PMR 1993. Kuala Lumpur: Kementerian Pendidikan Malaysia.

[2] Lembaga Peperiksaan Malaysia. 2002. Laporan Prestasi PMR 2002. Kuala Lumpur: Kementerian Pendidikan Malaysia.

[3] Elango Periasamy and Halimah Badioze Zaman. 2009. Augmented Reality as a Remedial Paradigm for Negative Numbers: Content Aspect. First International Visual Informatics Conference, IVIC 2009 371-381

[4] Naylor M. 2006. Integrating Math in Your Classroom. Accentuate the Negative. Teaching Pre K-8. ERIC 36(4): 34-35.

[5] Brumbaugh,K.,D. and Rock, D. 2006. Teaching secondary Mathematics.(Ed 3). Lawrence Erlbaum Associates: New Jersey.

[6] Victor Chen \& David Hung.2003. Learning Theories and IT in Instruction, in Dr. Tan Seng Chee \& Dr. Angela F.L. Wong (ed.). Teaching and Learning with Technology: Teory and Practice, pg. 82 - 100. Singapore: Pearson Prentice Hall.

[7] Carnellor, Y.2004. Encouraging Mathematical Success for Children with Learning Difficulties. Australia: Social Sciences Press.

[8] Terao, A., Sawaki, R., Hasegawa, M. \& Murohashi , H. 2005. Improving Skills of Addition and Subtraction Involving Negative Numbers Based on Cognitive Task Analysis and Assessment of Mental Representations of Negative Numbers: A Case Study of a Seventh-Grade

Student.http://www.cogsci.rpi.edu/CSJarchive/Proceedings/2005/d ocs/p2172.pdf [22 February 2008]

[9] Prather, R. W. \& Alibali, M. W. 2004.Understanding of Principles of Arithmetic with Positive and Negative Numbers.http://www.cogsci.northwestern.edu/cogsci2004/ma/ma2 97.pdf [4 September 2008]

[10] Stanford, S. 2003. Negative Numbers and Other Frauds. http://www.xeeatwelve.com/articles/negative_numbers.htm [23 January 2009]

[11] Alias Baba. 1999. Statistik Penyeludikan dalam Pendidikan dan Sains Sosial. Bangi: Penerbit Universiti Kebangsaan Malaysia.

[12] Mervis, L. \& Spagnolo, J. 1995. Assessment Book: A Guide for Developing Assessment programs in Illinois Schools.http://www.gower.k12.il.us/Staff/ASSESS/index.htm\#asse ssment [4 September 2008]

[13] Rose, C. M., Minton, L., and Arline, C.2007.Uncovering Student thinking in Mathematics. Corwin Press: California.

[14] Askew, M., and William, D.1995. Recent research in mathematics education 5 - 16. HMSO Publications: London. 